\title{
Evaluation of the Antimicrobial Efficacy of Chitosan Nano-Particles on Biofilm Eradication in Single Rooted Teeth Using Confocal Laser Scanning Microscope: A Comparative In-vitro Study
}

\section{Tarek Ali El-Mosalamy ${ }^{1 *}$, Shimaa Ismael Gawdat ${ }^{2}$ and Abeer A Saba ${ }^{2}$}

${ }^{1}$ Masters Degree Student, Faculty of Dentistry, Cairo University, Egypt

${ }^{2}$ Associate Professor of Endodontics, Faculty of Dentistry, Cairo University, Egypt

*Corresponding Author: Tarek Ali El-Mosalamy, Masters Degree Student, Faculty of Dentistry, Cairo University, Egypt.
Received: February 19, 2020

Published: March 13, 2020

(C) All rights are reserved by Tarek Ali

El-Mosalamy., et al.

\begin{abstract}
Objective: The purpose of this In-vitro study was to evaluate the antibacterial efficacy of sodium hypochlorite and nano-chitosan irrigations (CNPs) with two different irrigation techniques, conventional syringe irrigation (CSI) and Passive ultrasonic irrigation (PUI) on Enterococcus Faecalis biofilm reduction inside the infected dentinal tubules using confocal laser scanning microscope (CLSM).

Methods: Twenty eight teeth samples were bio-mechanically prepared, sterilized, and inoculated with E. faecalis (ATCC 29212) for

3 weeks. Specimens were then randomly divided into four groups $(n=7)$ according to the final irrigation protocol as follows: Group I, CSI with 2.6\% NaOCl; Group II, irrigation with 2.6\% NaOCl + PUI; Group III, CSI with $0.5 \%$ CNPs; while in Group IV, irrigation with $0.5 \%$ CNPs + PUI. Samples were then longitudinally sectioned to obtain a $4 \times 2 \mathrm{~mm}$ sized sections from the apical $1 / 3$ of the roots. E. faecalis biofilm reduction was finally evaluated using CLSM and at three different $100 \mu \mathrm{m}$ areas representing 3 depths inside the dentinal tubules.

Results: None of the four experimental groups could result in complete elimination of E. faecalis from the dentinal tubules. Group II ( $\mathrm{NaOCl}+\mathrm{PUI}$ ), III (CNPs), and IV (CNPs + PUI) all showed significantly higher biofilm reduction when compared to Group I ( $\mathrm{NaOCl})$ (P-value < 0.001). However there was no statistically significant difference between the three groups (P-value $>0.05$ ).

Conclusion: Active and passive CNPs irrigations showed superior antibacterial efficacy in comparison to $\mathrm{NaOCl}$, and were on bar with PUI activated $\mathrm{NaOCl}$, no improvement in the antibacterial efficacy could be obtained from using PUI to activate CNPs irrigation. Keywords: Chitosan; Nanopaticles; Antibacterial; Entrococcus Faecalis; Irrigation; Confocal Laser Microscope
\end{abstract}

\section{Introduction}

Microorganisms and their toxic metabolic byproducts play a major role in pulp and periapical disease. Although endodontic infections are generally polymicrobial in nature with many pathogenic species being involved, E. Faecalis is considered one of the most crucial and commonly involved specie. This can be attributed to its various survival and virulence potentials allowing it to resist treatment procedures and persist after root canal treatment [1]. Hence, proper disinfection of the root canal system including effective E. faecalis biofilm eradication is essential for the success of endodontic treatment.

Sodium hypochlorite irrigation is considered the most effective tool used to combat endodontic infections. Its excellent antimicrobial properties, tissue dissolving action, reasonable price, and adequate shelf life has made it an invaluable tool for overcoming the microbial challenge. However, its cytotoxcity, unpleasant taste, and odor remain a cause of concern [2].

In an effort to overcome the inherent drawbacks associated with the use of $\mathrm{NaOCl}$, Chitosan based irrigation have been suggest- ed as a possible alternative. Chitosan is a natural irrigant derived from chitin, a principle component of crustacean exoskeletons. It possesses a multitude of desirable properties such as being biocompatible, biodegradable, bioadhesive, together with excellent antimicrobial action, and no reported toxicity. Its broad spectrum antimicrobial action is mainly attributed its polycationic nature that allows it to interact with the negatively charged surface of bacteria, altering its cell permeability and resulting in the leakage of intracellular components and subsequent cell death [3]. Chitosan nano-form (CNPs) is suggested to further augment and enhance these desirable properties owing to the added advantages of its ultra-small size, increased surface area/mass ration, and enhanced chemical reactivity [4].

The complexity of the anatomy of the root canal space is another obstacle that may hinder the irrigant from reaching all spaces left untouched after mechanical instrumentation, areas such as isthmuses, ramifications, dentinal tubules, and recesses can act as an ecological niche for microorganisms [5]. Passive ultrasonic irrigation (PUI) is a common and readily available activation tool 
suggested to help enhance the flow of the irrigant throughout the entire root canal system, thus enhancing its overall activity and penetration. The ability of PUI to enhance the antimicrobial activity of $\mathrm{NaOCl}$ has been investigated in various studies with inconsistent result [6].

Up until now, the efficacy of CNPs as an endodontic irrigant for root canal disinfection has not been subjected to adequate scrutiny with further investigations still required; furthermore the effect of PUI on the penetration and subsequently the antimicrobial efficacy CNPs is yet to be explored. Hence this study aimed to evaluate the efficacy of CNPs as an irrigation solution when used with conventional syringe irrigation and when used with PUI in comparison to $\mathrm{NaOCl}$ when used with conventional syringe irrigation and when used with PUI, on E. faecalis biofilm reduction at 3 different $100 \mu \mathrm{m}$ areas representing 3 depths inside the infected dentinal tubules.

\section{Materials and Methods \\ Sample size calculation}

Based on a previous study by Jaiswal., et al. (2017) [3]. Sample size was calculated as 7 samples in each group using power $80 \%$ and $5 \%$ significance level. Sample size calculation was achieved using Power and Sample Size Calculation Software Version 3.1.2 (Vanderbilt University, Nashville, Tennessee, USA).

\section{Selection of samples}

Twenty eight human permanent single rooted teeth extracted due to either periodontal or orthodontic reasons were collected from the oral and maxillofacial department, Faculty of dentistry, Cairo University. Teeth were viewed by radiograph to confirm that they all had a single canal, no internal calcification, root resorption, or other anomalies. The external surfaces of the roots were then cleaned using a curette to remove any present calculus or periodontal tissues. Teeth were finally stored in saline solution until use.

\section{Preparation of samples}

Teeth were decoronated using a low speed diamond bur to obtain a uniform $15 \mathrm{~mm}$ tooth length. Patency of the canals were established using K-files (MANI, Matsutain, Seisakusho Co., Tochigi-Ken, Japan). The root canals were subsequently instrumented using Protaper Next rotary system(Dentsply Maillefer, Ballaigues, Switzerland) and up to file X4 (\#40/.06) at a speed of $300 \mathrm{rpm}$ and torque of $2 \mathrm{Ncm}$ using X-Smart Endo Motor (Dentsply Maillefer, Ballaigues, Switzerland) and in accordance with the manufacturer instructions. The canals were irrigated with $3 \mathrm{ml} 2.5 \% \mathrm{NaOCl}$ at a rate of $1 \mathrm{ml} / \mathrm{min}$ in between each instrument change and as a final flush using a $30 \mathrm{G}$ end vented needle reaching $2 \mathrm{~mm}$ short of the apex to deliver a total volume of $15 \mathrm{ml}$. A $1 \mathrm{ml}$ EDTA solution (Prevest Dentpro Ltd., Jammu, India) was then used to remove the smear layer from the canals, followed by a final flush of saline to inactivate the EDTA solution. The apical formina of the teeth were finally sealed with flowable composite and the samples sterilized by autoclaving for $15 \mathrm{~min}$ at $121^{\circ}$.

Inoculation of samples with Enterococcus faecalis

Twenty microns of E. faecalis strain (ATCC 29212) suspension was used to infect the root canals using a micropipette, canals were then immersed in brain heart infusion broth media (BHI). Infected teeth were subsequently placed in flasks and incubated aerobically using Heratherm TM Advanced Protocol Microbiological Incubator (Thermo Fisher Scientific, Waltham, Massachusetts, USA) for 21 days at $37^{\circ}$ and under gentle shaking.

\section{Chitosan nano-particles (CNPS) preparation}

CNPs were prepared using the ionic gelation method as described in a previous study by Elshoky., et al. (2018) [7] with modifications. First, a solution of $50 \mathrm{ml}$ of $0.5 \%$ chitosan ( $5 \mathrm{mg} / \mathrm{ml}$ ) was prepared by dissolving CS in $2 \%(\mathrm{v} / \mathrm{v}$ ) acetic acid solution in deionized water under magnetic stirring. The $\mathrm{pH}$ was adjusted to $\mathrm{pH} 4.8$ with $0.5 \mathrm{M} \mathrm{NaOH}$, followed by constant stirring for $30 \mathrm{~min}$. Next, $6 \mathrm{ml}$ of TPP solution $(27.5 \mathrm{mg} / \mathrm{ml})$ was added under stirring (800 $\mathrm{rpm}$ ) to form the nanoparticles. A suspension of $0.5 \%$ CNPs was finally obtained and further examined to confirm a particle size average of $81.07 \mathrm{~nm}$ and zeta potential of $51.3 \mathrm{mV}(>30)$. The CNPs suspension was then stored in a refrigerator until use.

\section{Allocation and intervention for each group}

The infected teeth were then randomly divided into 4 equal groups according the final irrigation protocol $(\mathrm{n}=7)$ as follows: Group I, (NaOCl); Group II, (NaOCl+ PUI); Group III, (CNPs); and Group IV (CNPs + PUI). All the infected teeth were subjected to a standardized irrigation protocol of alternating 30 seconds of irrigation followed by either 30 seconds of activation using PUI or rest as described by Mohmmed., et al. (2017) [8]. A total of $3 \mathrm{ml}$ of the respective solution was delivered in each of the groups using a $30 \mathrm{G}$ needle reaching $2 \mathrm{~mm}$ from the working length while being moved in an up and down motion within $2 \mathrm{~mm}$ amplitude during irrigation.

Evaluation of biofilm reduction using confocal laser scanning microscope (CLSM): (Live/Dead) essay

The samples from each group were sectioned to obtain $4 \times 2 \mathrm{~mm}$ size sections with $2 \mathrm{~mm}$ thickness from the apical third of each sample using IsoMet ${ }^{\mathrm{TM}}$ precision sectioning saw (Buehler Ltd., Lake Bluff, IL, USA) figure 1. Sections from each group were then stained with fluorescent LIVE/DEAD Bac Light Bacterial Viability stain (Sigma-Aldrich, St. Louis, Missouri, USA) and viewed using a confocal laser scanning microscope (Carl Zeiss, Göttingen, Germany). Simultaneous dual-channel imaging was used to display the green 
fluorescence (live cells) and red fluorescence (dead cells). Quantification of the CLSM images was done at two to three random areas using ZEN 2012 (blue edition) software (Carl Zeiss, Göttingen, Germany). The fluorescence from the live and dead bacterial cell was calculated by measuring the fluorescent light intensity at three areas at $100,200,300 \mu \mathrm{m}^{2}$ from the canal surface figure 2. Percentage of dead bacteria was calculated at each area using the following equation:

Percentage of dead cells $=\frac{\text { Intensity of red fluorescence }}{\text { Intensity of red fluorescence }+} \times 100$
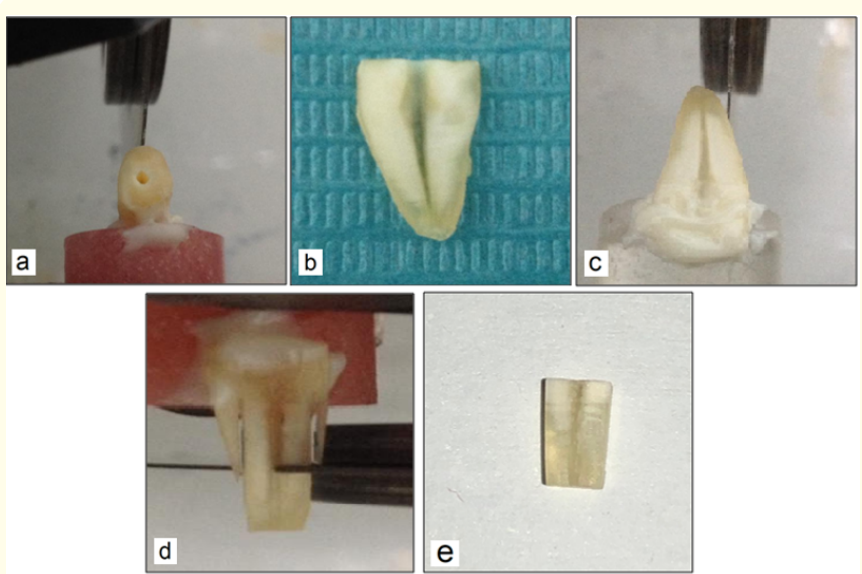

Figure 1: (a-e) Showing the process of cutting the specimen to obtain a uniform $2 \times 4 \mathrm{~mm}$ section from the apical $1 / 3$ using IsoMetTM precision sectioning saw.

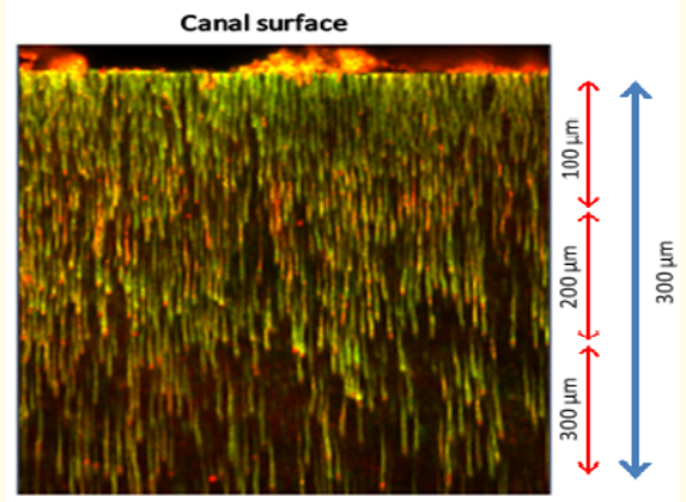

Figure 2: Illustration showing the intended measuring areas for each CLSM image.

\section{Statistical analysis}

Numerical data were explored for normality by checking the data distribution, calculating the mean and median values and using Kolmogorov-Smirnov and Shapiro-Wilk tests. Data showed parametric distribution so; it was represented by mean and standard deviation (SD) values. Two-way mixed model ANOVA was used to study the effect of different tested variables and their interaction on percentage of dead cells (\%). The significance level was set at $\mathrm{P} \leq 0.05$ within all tests. Statistical analysis was performed with IBM $^{\circledR}$ SPSS $^{\circledR}$ Statistics Version 25 for Windows.

\section{Results}

The result for $E$. faecalis biofilm reduction at all the areas tested $100,200,300 \mu \mathrm{m}^{2}$ demonstrated a statistically significant difference between the groups at each respective area $(p<0.001)$. Pairwise comparison of the four groups revealed no statistically significant difference between Group II ( $\mathrm{NaOCl}+\mathrm{PUI})$, Group III (CNPs), and Group IV (CNPs + PUI), However all three groups showed significantly higher mean bacterial reduction at all areas tested respec-

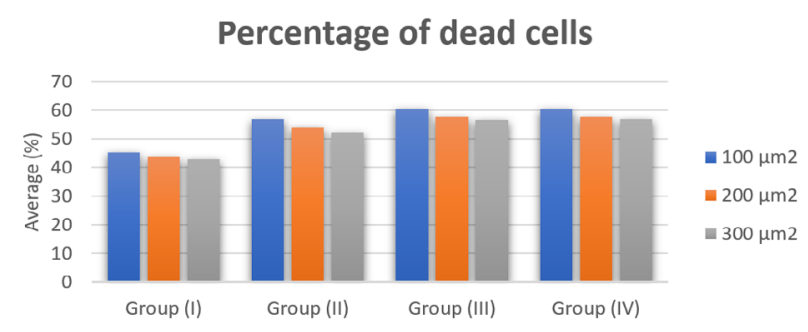

Figure 3: Bar chart showing average percentage of dead cells (\%) for different groups within different areas from the canal dentin surface.

\begin{tabular}{|c|c|c|c|c|c|}
\hline \multirow{2}{*}{$\begin{array}{c}\text { Area From } \\
\text { The } \\
\text { Surface }\end{array}$} & \multicolumn{4}{|c|}{ Irrigation Type (Mean \pm SD) } & \multirow{2}{*}{$\begin{array}{c}\text { P- } \\
\text { Value }\end{array}$} \\
\hline & $\begin{array}{l}\text { Group } \\
\text { (I) }\end{array}$ & $\begin{array}{l}\text { Group } \\
\text { (II) }\end{array}$ & $\begin{array}{l}\text { Group } \\
\text { (III) }\end{array}$ & $\begin{array}{l}\text { Group } \\
\text { (IV) }\end{array}$ & \\
\hline $100 \mu \mathrm{m}$ & $\begin{array}{c}45.17 \pm \\
6.76^{\mathrm{Ba}} \\
\end{array}$ & $\begin{array}{c}56.76 \pm \\
1.61^{\mathrm{Aa}}\end{array}$ & $\begin{array}{c}60.41 \pm \\
4.78^{\mathrm{Aa}} \\
\end{array}$ & $\begin{array}{c}60.37 \pm \\
3.90^{\mathrm{Aa}} \\
\end{array}$ & $<0.001^{*}$ \\
\hline $200 \mu \mathrm{m}$ & $\begin{array}{c}43.72 \pm \\
7.44^{\mathrm{Bb}} \\
\end{array}$ & $\begin{array}{c}53.74 \pm \\
2.34^{\mathrm{Ab}}\end{array}$ & $\begin{array}{c}57.59 \pm \\
5.03^{\mathrm{Ab}} \\
\end{array}$ & $\begin{array}{c}57.58 \pm \\
4.67^{\mathrm{Ab}}\end{array}$ & $<0.001^{*}$ \\
\hline $300 \mu \mathrm{m}$ & $\begin{array}{c}42.85 \pm \\
7.66^{\mathrm{Bb}} \\
\end{array}$ & $\begin{array}{c}52.00 \pm \\
2.70^{A c} \\
\end{array}$ & $\begin{array}{c}56.55 \pm \\
4.76^{\mathrm{Ac}} \\
\end{array}$ & $\begin{array}{c}56.72 \\
\pm 4.49^{\mathrm{Ab}} \\
\end{array}$ & $<0.001^{*}$ \\
\hline P-value & $<0.001^{*}$ & $<0.001^{*}$ & $<0.001^{*}$ & $<0.001^{*}$ & \\
\hline
\end{tabular}

Table 1: Mean \pm standard deviation (SD) of percentage of dead cells (\%) for different groups and different areas from the surface.

Different upper and lowercase superscript letters indicate a statistically significant difference within the same horizontal row and vertical column respectively*; significant ( $p \leq 0.05)$ ns; nonsignificant $(\mathrm{p}>0.05)$.

tively in comparison to Group I $(\mathrm{NaOCl})(\mathrm{p}<0.001)$. (Table 1 and Figure 3).

\footnotetext{
${ }^{\circledR}$ IBM Corporation, NY, USA.

${ }^{\circledR}$ SPSS, Inc., an IBM Company
} 
Evaluation of the Antimicrobial Efficacy of Chitosan Nano-Particles on Biofilm Eradication in Single Rooted Teeth Using Confocal Laser Scanning Microscope: A Comparative In-vitro Study

Regarding the overall effect of the depth inside the dentinal tubules on irrigant efficacy and $E$. faecalis biofilm reduction, the highest mean percentage of dead cells was measured in the first $(100$ $\mu \mathrm{m}^{2}$ ) from the canal surface and was significantly higher than that measured in the second area $\left(100-200 \mu \mathrm{m}^{2}\right)$, which in turn had a

\begin{tabular}{|c|c|c|c|}
\hline \multicolumn{3}{|c|}{ Area from the Surface (Mean \pm SD) } & \multirow{2}{*}{ P-value } \\
\cline { 1 - 3 }${\mathbf{1 0 0} \boldsymbol{\mu} \mathbf{m}^{\mathbf{2}}}^{\mathbf{2 0 0}} \boldsymbol{\mu m}^{\mathbf{2}}$ & $\mathbf{3 0 0} \boldsymbol{\mu m}^{\mathbf{2}}$ & \\
\hline $55.62 \pm 7.96^{\mathrm{A}}$ & $53.13 \pm 7.83^{\mathrm{B}}$ & $52.03 \pm 7.80^{\mathrm{C}}$ & $<0.001^{*}$ \\
\hline
\end{tabular}

Table 2: Mean \pm standard deviation (SD) of percentage of dead cells (\%) for different areas from the surface

Different superscript letters indicate a statistically significant difference within the same horizontal row*; significant $(p \leq 0.05) n s ;$ non-significant $(p>0.05)$.

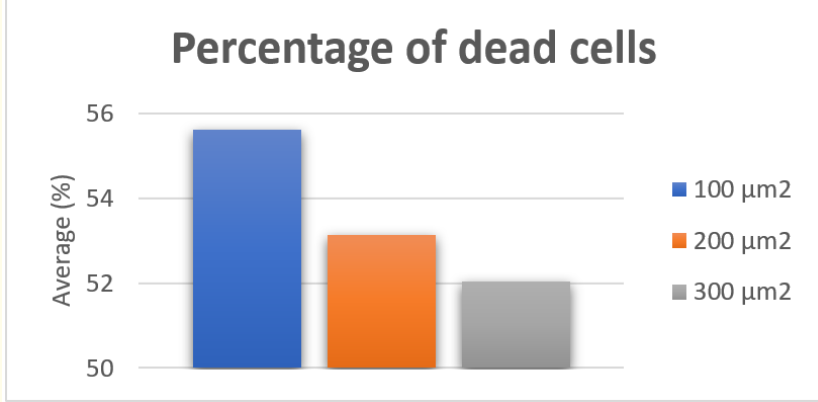

Figure 4: Bar chart showing overall average percentage of dead cells (\%) for different areas from the canal dentin surface.

significantly higher mean percentage of dead cells than those measured at the deepest area $\left(200-300 \mu \mathrm{m}^{2}\right)$ from the dentin surface (P $<0.001$ ) (Table 2 and Figure 4).

As for the overall E. faecalis biofilm reduction measured at the entire area $\left(0-300 \mu \mathrm{m}^{2}\right)$, the highest bacterial reduction was recorded in Group IV (CNPs + PUI), followed by Group III (CNPs), and then Group II ( $\mathrm{NaOCl}+\mathrm{PUI})$, the least bacterial reduction was recorded in Group I ( $\mathrm{NaOCl})$. Pairwise comparison of showed that

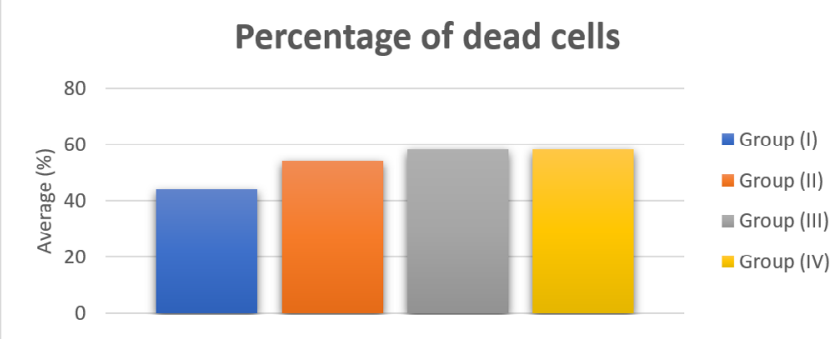

Figure 5: Bar chart showing overall mean percentage of dead bacterial cells $(\%)$ at the area $\left(0-300 \mu \mathrm{m}^{2}\right)$.

\begin{tabular}{|c|c|c|c|c|c|c|c|c|}
\hline \multirow{3}{*}{\begin{tabular}{|l} 
Outcome \\
Biofilm reduc-
\end{tabular}} & \multicolumn{8}{|c|}{ Irrigation type (Mean \pm SD) } \\
\hline & \multicolumn{2}{|c|}{ Group I } & \multicolumn{2}{|c|}{ Group II } & \multicolumn{2}{|c|}{ Group III } & \multicolumn{2}{|c|}{ Group IV } \\
\hline & Mean & SD & Mean & SD & Mean & SD & Mean & SD \\
\hline $\begin{array}{l}\text { tion at area } \\
0-300 \mu \mathrm{m} \\
\text { from the canal } \\
\text { surface }\end{array}$ & 43.91 & \pm 7.18 & 54.17 & \pm 2.97 & 58.18 & \pm 5.01 & 58.22 & \pm 4.54 \\
\hline
\end{tabular}

Table 3: Mean and SD of overall bacterial reduction in all groups.
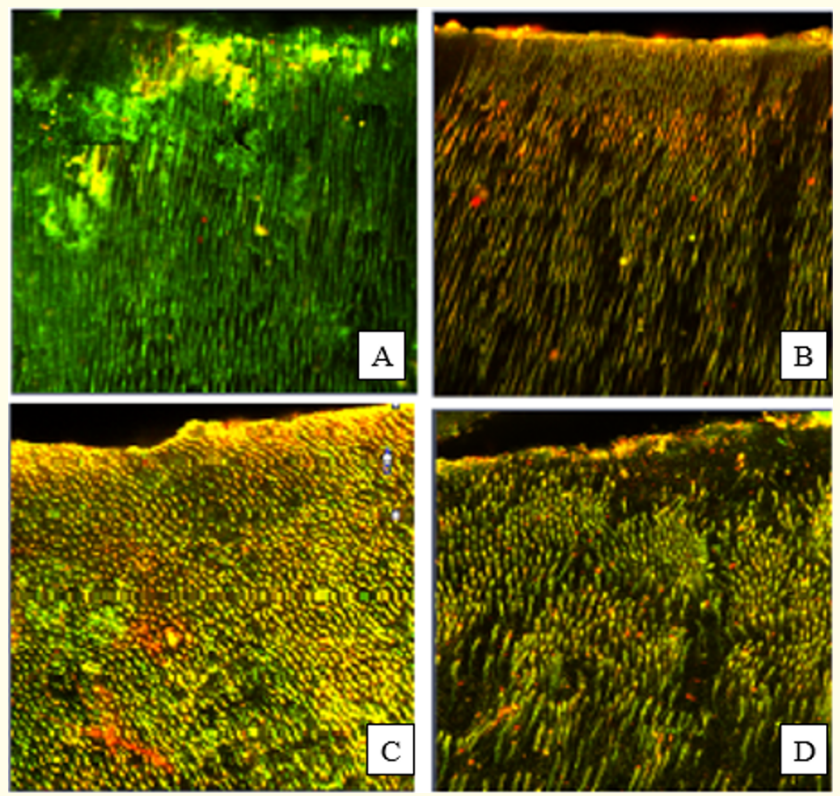

Figure 6: CLSM images with 40x lens representing biofilm reduction, Green color represents living cells while Red represents dead cell. (A) Group I (NaOCl), (B) Group II

Group II (NaOCl+ PUI), Group III (CNPs), and Group IV (CNPs + PUI) all showed significantly higher values when compared to Group I $(\mathrm{NaOCl})$, however there was no significant difference between the three groups. (Table 3) Figure 5 and 6)

\section{Discussion}

The primary goal of endodontic treatment is to prevent or treat apical periodontitis. Since one of the main causes of apical periodontitis is failure to remove and/or keep the root canal space free of micro-organisms, proper disinfection of root canal system is of utmost important for the success of endodontic treatment [9]. A variety of studies have emphasized the persistence of micro-organisms after root canal treatment as a major cause of treatment failure [10-12].

E. faecalis was chosen to infect the root canal due to their inherent antimicrobial resistance; their ability to adapt to changing environment, resist the disinfection procedures and persist after treatment [3]. It's also considered one of the most common microorganism isolated from root canals especially in cases with persis- 
tent periapical periodontitis [13]. E. faecalis strain ATCC 29212 was chosen due to its ability to adhere, aggregate and grow to form a biofilm, thus improving its survival potential and rendering it more resistant to anti-microbial agents [14]

The apical region of the root canals was selected as a test area for its complex anatomy, containing a high percentage of accessory canals and ramification that can harbors a substantial bacterial population. Furthermore the phenomenon of vapor lock in the apical third is another factor that can hinder the irrigant from achieving direct contact with the infected dentin. Thus its the least exposed area to the effect of the irrigating solutions when compared to the coronal and middle areas which are exposed to better flow and higher volume of the irrigating solution [15]. Moreover, it's been recognized that disinfection of the root canal system at the apical area is one of the most critical therapeutic measures for the treatment of apical periodontitis [16-17].

Chitosan based irrigation is an intriguing new intervention with promising antibacterial properties. It's nano-particles variant is suggested to provide superior anti-microbial properties with low potential to produce microbial resistance [18]. Its augmented antimicrobial properties can be attributed to its ultra-small size, large surface area/mass ratio, and increased chemical reactivity. Its biocompatibility, enhanced antimicrobial potential and lack of reported toxicity thus makes it an attractive tool to supplement the disinfection of the root canal system and perhaps act as an alternative to $\mathrm{NaOCl}$ irrigation [19].

Activation of the irrigation solution has been advocated to help send the irrigant throughout the root canal system, thus improving its penetration and allowing it to reach further and deeper into bacteria infested areas. PUI was chosen as its one of the most common and readily available methods of irrigant agitation [8]. The irrigation protocol of alternative periods of irrigation and activation was chosen in accordance to previous study by Mohmmed., et al. (2017) [8]. It allowed for standardization of the irrigation time and volume during both passive and active irrigation.

The present study showed that none of the four experimental groups could result in complete elimination of E. faecalis from the dentinal tubules. This was expected since only a final flush of the solutions was used. It also demonstrated a significantly higher antibacterial activity of the intervention groups in comparison to the positive control $(\mathrm{NaOCl})$ at all the areas examined.

The effect of PUI on $\mathrm{NaOCl}$ antibacterial efficacy is contradictory in literature. Studies concluding a lack of a significant increase of the antimicrobial efficacy of $\mathrm{NaOCl}$ when used in conjunction with PUI mostly attributed their results to the inability of PUI to overcome the surface tension of the irrigant and provide a cavitation effect powerful enough to allow for elimination of hidden bacteria and subsequently provide a significant difference in the irrigant antibacterial action. (20 - 23). However, other studies successfully demonstrated a significant increase in the antimicrobial effect of $\mathrm{NaOCl}$ when used in conjunction with PUI(24 - 28(who demonstrated a significant increase in the antimicrobial effect of $\mathrm{NaOCl}$ when used in conjunction with PUI.

The significant difference between observed between $(\mathrm{NaOCl})$ group and $(\mathrm{NaOCl}+\mathrm{PUI})$ group in our study, both at the canal surface and at the different depths inside the dentinal tubules could be accredited the bio-mechanical and thermal effect of ultrasonic activation. The bio-mechanical effect is most commonly attributed to two physical phenomena, which are acoustic streaming and micro-cavitation. Acoustic streaming is used to describe the rapid circular movement of the irrigant around the vibrating file, while micro-cavitation refers to the implosion of pre-existing vapor containing bubbles in the irrigant. This in turns result in formation of shockwaves characterized by rapid changes in pressure and a high amplitude, eventually resulting in disruption of bacterial biofilms, rupture of bacterial cell wall, and removal of debris [29]. The thermal effect is due to the rise of temperature of $\mathrm{NaOCl}$ that is associated with the introduction of an ultrasonic tip inside the solution for a period of time [6]. A variety of previous studies have confirmed the positive effect of heating $\mathrm{NaOCl}$ on its antimicrobial action with some suggesting preheating of $\mathrm{NaOCl}$ as less toxic alternative to increasing its concentration $[6,29]$.

Similarly, the lack of a significant difference between (CNPs) group and (CNPs+PUI) can be justified through failure of the previously described mechanisms to improve the antimicrobial efficacy of chitosan. Chitosan higher visocisity could have led to the failure of PUI to overcome the higher surface tension and result in sufficient improvement in the cavitations and bubbling effect and subsequently the antibacterial efficacy. The thermal effect of PUI also lead to little to no improvement of the antibacterial efficacy as the ideal antibacterial action of chitosan is achieved at acidic $\mathrm{pH}$ values and at a temperature range of $20-37^{\circ} \mathrm{C}$ and an increase beyond that point might not have led to any advantageous effect [30]. A study examining the effect of heat on the antibacterial properties of Cross-Linked Chitosan-Glutaraldehyde(CLCG) has even shown a slight decrease in its antibacterial action in temperatures range from $40^{\circ}-70^{\circ} \mathrm{C}[31]$.

The superior effect of CNPs groups over $\mathrm{NaOCl}$, both at the surface and at different depths can be attributed to the polycationic nature that allows it to interact with the negatively charged surface of bacteria, altering cell permeability and resulting in the leakage of intracellular components. Another proposed mechanism is the binding of chitosan to microbial DNA, leading to inhibition of mRNA and protein synthesis. This mechanism assumes the ability of chitosan molecules to pass through the bacterial cell wall and reach the plasma membrane. This mechanism was confirmed by the results of a study by LIU., et al. (2001) [32] which confirmed 
the presence of chitosan oligomers inside E-coli bacteria using Confocal Laser Scanning Microscope. However, despite being accepted as a possible mechanism the prevailing contention is that chitosan acts mainly on the outer membrane rather as a penetrating material. The previously discussed characteristic antibacterial properties of chitosan are further enhanced through the use of its nano-particles variant. CNPs irrigation provided a greater chemical reactivity along with increased surface/volume ratio leading to more particles being readily available for reaction and further augmenting its polycationic/polyanionic mechanism of action.

These result were in contrast to a study by Jaiswal., et al. (2017) [3] who concluded that although $0.2 \%$ Chitosan showed significant antibacterial effect, it was not on bar with that of $5 \% \mathrm{NaOCl}$, Shenoi., et al. (2016) [33] and Yadav., et al. (2017) [34] also compared the antimicrobial efficacy of $\mathrm{NaOCl} 3 \%$ to Chitosan $1 \%$ and $0.5 \%$ respectively, and found them to have similar antibacterial efficacy. However the previously mentioned studies examined the efficacy of the bulk form of Chitosan rather than its nano-particles variant and used a higher concentration of $\mathrm{NaOCl}$. Roshdy., et al. (2018) [4] examined the antibacterial action of $3 \%$ CNPs using colony forming units (CFUs) and concluded that the antibacterial action of $3 \%$ CNPs on E. faecalis is similar to that of $2.5 \% \mathrm{NaOCl}$. The higher nano-particles concentration used in that study might have inversely effected the antibacterial action of the solution due to agglomeration of the nanoparticle within the suspension, thus resulting in a larger particles size and subsequently negating some of the positive effects of the nano-form [35].

\section{Conclusion}

Within the limitations of this study, it could be concluded that none of the root canal irrigation methods resulted in complete $E$. faecalis biofilm eradication. Activation of $\mathrm{NaOCl}$ using PUI technique increased its biofilm eradication capability at all depths tested. CNPs irrigant showed better biofilm reduction efficacy in comparison to sodium hypochlorite and a similar efficacy to activated sodium hypochlorite with PUI at all depths tested. Activation of CNPs irrigant using PUI technique did not result in a significant improvement of its antibacterial efficacy at all the depths tested.

\section{Conflict of Interest}

The authors deny any conflicts of interest in this study.

\section{Bibliography}

1. Kayaoglu G., et al. "Antibacterial activity of Propolis versus conventional endodontic disinfectants against Enterococcus faecalis in infected dentinal tubules". Journal of Endodontics 37.3 (2011): 376-381.

2. Mathew ST. "Risks and Management of Sodium Hypochlorite in Endodontics". Journal of Oral Hygiene and Health 3.3 (2015): 3-7.
3. Jaiswal N., et al. "Evaluation of antibacterial efficacy of Chitosan, Chlorhexidine, Propolis and Sodium hypochlorite on Enterococcus faecalis biofilm: An In vitro study". Journal of Clinical and Expermental Dentistry 9.9 (2017): e1066.

4. Roshdy NN., et al. "Assessment of antibacterial activity of $2.5 \%$ $\mathrm{NaOCl}$, chitosan nano-particles against Enterococcus faecalis contaminating root canals with and without diode laser irradiation: an In vitro study". Acta Odontologica Scandinavica (2018): 1-5.

5. Spagnuolo G. "Microcomputed Tomography Analysis of Mesiobuccal Orifices and Major Apical Foramen in First Maxillary Molars". Open Dental Journal 6.1 (2012):118-125.

6. Mozo S., et al. "Review of ultrasonic irrigation in endodontics: Increasing action of irrigating solutions". Medicina Oral Patologia Oral y Cirugia Bucal 17.3 (2012).

7. Elshoky HA., et al. "Ascorbic acid prevents cellular uptake and improves biocompatibility of chitosan nanoparticles". International Journal of Biological Macromolecules 115 (2018): 358366.

8. Mohmmed SA., et al. "Confocal laser scanning, scanning electron, and transmission electron microscopy investigation of Enterococcus faecalis biofilm degradation using passive and active sodium hypochlorite irrigation within a simulated root canal model". Microbiologyopen Journal 6.4 (2017): 1-9.

9. Claus Löst., et al. "Quality guidelines for endodontic treatment: consensus report of the European Society of Endodontology". International Endodontic Journal. 39.12 (2006): 921-930.

10. Mohan G., et al. "Histobacteriology Of Teeth with Failed Root Canal Treatment-A Pilot Study". Oral Health (2017).

11. Al-Fouzan K., et al. "Histological evaluation of the root apices of failed endodontic cases". Saudi Endodontic Journal 5.2 (2015): 120.

12. Tabassum S and Khan FR. "Failure of endodontic treatment: The usual suspects". Europian Journal of Dentistry 10.1 (2016): 144-147.

13. Sánchez-Sanhueza G., et al. "Enterococcus spp. isolated from root canals with persistent chronic apical periodontitis in a Chilean population". Brazilian Journal of Oral Science 14.3 (2015): 240-245.

14. Mohamed JA and Huang DB. "Biofilm formation by enterococci”. Journal of Medical Microbiology 56.12 (2007): 1581-1588. 
15. Looney SW., et al. "Effect of Vapor Lock on Root Canal Debridement by Using a Side-vented Needle for Positive-pressure Irrigant Delivery". Journal of Endodontic 36.4 (2010):745-750.

16. Siqueira JF and Rôças IN. "Clinical Implications and Microbiology of Bacterial Persistence after Treatment Procedures". Journal of Endodontic 34.11 (2008).

17. Tziafas D., et al. "Preparation prerequisites for effective irrigation of apical root canal: A critical review". Journal of clinical and Expermental Dentistry 9.10 (2017): e1256-e1263.

18. Ibrahim AI., et al. "Use of antibacterial nanoparticles in Endodontics”. South African Dental Journal 72.3 (2017): 105-112.

19. Ing LY., et al. "Antifungal Activity of Chitosan Nanoparticles and Correlation with Their Physical Properties". International Journal of Biomatererial (2012): 1-9.

20. Cheng X., et al. "Bactericidal Effect of Er: YAG Laser-Activated Sodium Hypochlorite Irrigation Against Biofilms of Enterococcus faecalis Isolate from Canal of Root-Filled Teeth with Periapical Lesions". Photomedicine and Laser Surgery 35.7 (2017): 386-392.

21. Mohmmed SA., et al. "Investigations into in situ Enterococcus faecalis biofilm removal by passive and active sodium hypochlorite irrigation delivered into the lateral canal of a simulated root canal model". International Endodontic Journal 51.6 (2018): 649-662.

22. Mohmmed SA., et al. "Confocal laser scanning, scanning electron, and transmission electron microscopy investigation of Enterococcus faecalis biofilm degradation using passive and active sodium hypochlorite irrigation within a simulated root canal model". Microbiologyopen 6.4 (2017): 1-9.

23. Macedo RG., et al. "Cavitation measurement during sonic and ultrasonic activated irrigation". Journal of Endodontics 40.4 (2014): 580-583.

24. Tardivo D., et al. "Antibacterial efficiency of passive ultrasonic versus sonic irrigation". Ultrasonic root canal irrigation". Odontostomatol Trop 33.129 (2010): 29-35.

25. Alves FRF, et al. "Disinfecting oval-shaped root canals: Effectiveness of different supplementary approaches". Journal of Endodontics 37.4 (2011): 496-501.

26. Betancourt P., et al. "Effectiveness of low concentration of sodium hypochlorite activated by Er,Cr:YSGG laser against Enterococcus faecalis biofilm". Lasers and Medical Science 34.2 (2019): 247-254.
27. Huque Kota., et al. "Bacterial eradication from root dentine by ultrasonic irrigation with sodium hypochlorite". International Endodontic Journal 31.4 (2003): 242-250.

28. Harrison AJ., et al. "The effect of ultrasonically activated irrigation on reduction of Enterococcus faecalis in experimentally infected root canals". International Endodontic Journal 43.11 (2010): 968-977.

29. Macedo RG., et al. "Cavitation measurement during sonic and ultrasonic activated irrigation". Journal of Endodontics 40.4 (2014): 580-583.

30. Ardila N., et al. "Effect of Chitosan Physical Form on Its Antibacterial Activity Against Pathogenic Bacteria". Journal of Food Science 82.3 (2017): 679-686.

31. Li B., et al. "Synthesis, characterization, and antibacterial activity of cross-linked chitosan-glutaraldehyde". Marine Drugs 11.5 (2013):1534-1552.

32. Fei Liu X., et al. "Antibacterial action of chitosan and carboxymethylated chitosan". J Appl Polym Sci. 79.7 (2001):1324-1335.

33. Shenoi PR., et al. "In vitro evaluation of the antimicrobial efficacy of chitosan and other endodontic irrigants against Enterococcus faecalis". General Dentistry 64.5 (2019): 60-63.

34. Yadav P., et al. "Evaluation of Antimicrobial and Antifungal efficacy of Chitosan as endodontic irrigant against Enterococcus Faecalis and Candida Albicans Biofilm formed on tooth substrate (2017).

35. Ashraf MA., et al. "Effects of size and aggregation/agglomeration of nanoparticles on the interfacial/interphase properties and tensile strength of polymer nanocomposites". Nanoscale Research Letters 13.1 (2018): 214.

\section{Assets from publication with us}

- Prompt Acknowledgement after receiving the article

- Thorough Double blinded peer review

- Rapid Publication

- Issue of Publication Certificate

- High visibility of your Published work

Website: www.actascientific.com/

Submit Article: www.actascientific.com/submission.php Email us: editor@actascientific.com

Contact uS: +919182824667 